Article

\title{
Efficiency of Iron-Based Oxy-Hydroxides in Removing Antimony from Groundwater to Levels below the Drinking Water Regulation Limits
}

\author{
Konstantinos Simeonidis ${ }^{1}$, Vasiliki Papadopoulou ${ }^{1}$, Sofia Tresintsi ${ }^{1}$, Evgenios Kokkinos ${ }^{1}$, \\ Ioannis A. Katsoyiannis ${ }^{2}$, Anastasios I. Zouboulis ${ }^{2}$ and Manassis Mitrakas ${ }^{1, *}$ \\ 1 Department of Chemical Engineering, Aristotle University of Thessaloniki, 54124 Thessaloniki, Greece; \\ ksime@physics.auth.gr (K.S.); papadovm8@gmail.com (V.P.); tresintsi@yahoo.gr (S.T.); \\ kokkinosevgenios@yahoo.gr (E.K.) \\ 2 Department of Chemistry, Aristotle University of Thessaloniki, 54124 Thessaloniki, Greece; \\ katsogia@chem.auth.gr (I.A.K.); zoubouli@chem.auth.gr (A.I.Z.) \\ * Correspondence: manasis@eng.auth.gr; Tel.: +30-231-099-6248
}

Academic Editor: Marc A. Rosen

Received: 22 November 2016; Accepted: 5 February 2017; Published: 10 February 2017

\begin{abstract}
This study evaluates the efficiency of iron-based oxy-hydroxides to remove antimony from groundwater to meet the requirements of drinking water regulations. Results obtained by batch adsorption experiments indicated that the qualified iron oxy-hydroxide ( $\mathrm{FeOOH})$, synthesized at $\mathrm{pH} 4$ for maintaining a high positive charge density $\left(2.5 \mathrm{mmol} \mathrm{OH}^{-} / \mathrm{g}\right)$ achieved a residual concentration of $\mathrm{Sb}(\mathrm{III})$ below the EU drinking water regulation limit of $5 \mu \mathrm{g} / \mathrm{L}$ by providing an adsorption capacity of $3.1 \mathrm{mg} / \mathrm{g}$. This is more than twice greater compared either to similar commercial FeOOHs (GFH, Bayoxide) or to tetravalent manganese feroxyhyte (Fe-MnOOH) adsorbents. In contrast, all tested adsorbents failed to achieve a residual concentration below $5 \mu \mathrm{g} / \mathrm{L}$ for $\mathrm{Sb}(\mathrm{V})$. The higher efficiency of the qualified $\mathrm{FeOOH}$ was confirmed by rapid small-scale column tests, since an adsorption capacity of $3 \mathrm{mg} \mathrm{Sb}(\mathrm{III}) / \mathrm{g}$ was determined at a breakthrough concentration of $5 \mu \mathrm{g} / \mathrm{L}$. However, it completely failed to achieve $\mathrm{Sb}(\mathrm{V})$ concentrations below $5 \mu \mathrm{g} / \mathrm{L}$ even at the beginning of the column experiments. The results of leaching tests classified the spent qualified $\mathrm{FeOOH}$ to inert wastes. Considering the rapid kinetics of this process (i.e., $85 \%$ of total removal was performed within $10 \mathrm{~min}$ ), the developed qualified adsorbent may be promoted as a prospective material for point-of-use $\mathrm{Sb}$ (III) removal from water in vulnerable communities, since the adsorbent's cost was estimated to be close to $30 \pm 3.4 € / 10^{3} \mathrm{~m}^{3}$ for every $10 \mu \mathrm{g} \mathrm{Sb}(\mathrm{III}) / \mathrm{L}$ removed.
\end{abstract}

Keywords: antimony; drinking water; adsorption; iron oxy-hydroxides; column tests; surface charge

\section{Introduction}

Antimony is classified as a toxic compound and as a high priority pollutant, especially for water supplies used for drinking purposes [1]. Particularly, international organizations (US EPA, EU) have established a very low maximum permissible contaminant level ( 6 and $5 \mu \mathrm{g} / \mathrm{L}$, respectively) for $\mathrm{Sb}$ species regarding the consumption of safe drinking water [2,3]. Nevertheless, particular attention has not been dedicated to the understanding of $\mathrm{Sb}$ aqueous chemistry, as well as to the development of respective methods for its efficient removal to levels below the regulation limits. This can be attributed to the lower frequency of the presence of $\mathrm{Sb}$ in aquatic systems, which is a consequence of its limited solubility, when compared to aquatic species of other elements of the same group in the Periodic Table, such as arsenic and phosphorus [4]. Still, high concentrations of $\mathrm{Sb}$ were reported in water sources near hot springs, in areas with specific industrial activities such as the production of flame retardants, 
batteries, chemicals, ceramics, etc., as well as in certain mining fields. In the last case, the presence of antimony is usually combined with high arsenic concentrations, mainly originating from sulfide ores [5].

In natural waters, $\mathrm{Sb}$ can be found in two oxidation states, i.e., as $\mathrm{Sb}(\mathrm{III})$ and $\mathrm{Sb}(\mathrm{V})$, depending on the respective redox potential of the aquatic reservoir. Under oxic conditions, $\mathrm{Sb}(\mathrm{V})$ oxyanions are the dominant forms, while the percentage of trivalent species, considered to be more toxic, becomes significant only in less oxygenated systems. The speciation of $\mathrm{Sb}(\mathrm{V})$ is determined by its coordination with oxygen atoms which is rather different from the corresponding $\mathrm{As}(\mathrm{V})$ and $\mathrm{P}(\mathrm{V})$ oxyanions. More specifically, due to its larger ionic radius and lower charge density, $\mathrm{Sb}(\mathrm{V})$ is coordinated in octahedral geometry, unlike $\mathrm{As}(\mathrm{V})$ and $\mathrm{P}(\mathrm{V})$ which favor a tetrahedral formation. Accordingly, $\mathrm{Sb}(\mathrm{OH})_{6}{ }^{-}$is the dominant species of $\mathrm{Sb}(\mathrm{V})$ in the common $\mathrm{pH}$ range of natural waters. On the other side, neutral $\mathrm{Sb}(\mathrm{OH})_{3}$ species appear as the hydrolyzed forms of $\mathrm{Sb}(\mathrm{III})$.

A variety of methods have been proposed for the removal of $\mathrm{Sb}$ from water, with most of them being adapted by similar approaches as applied in the case of arsenic removal. In summary, coagulation, adsorption, oxidation, ion-exchange, membrane separation and bioremediation techniques are commonly discussed in the respective literature studies [6,7]. Coagulation and co-precipitation methods usually incorporate the use of low-cost ferric or aluminum salts to successively capture both $\mathrm{Sb}(\mathrm{III})$ and $\mathrm{Sb}(\mathrm{V})$ species [8-11]. Relevant studies indicate that the removal of $\mathrm{Sb}(\mathrm{III})$ is more favorable than that of $\mathrm{Sb}(\mathrm{V})$, due to the increasing mobility of pentavalent species at $\mathrm{pH}$ values above 5 and the strong competition for adsorbing sites of specific co-existing anions, such as phosphate, silicate, and bicarbonate, commonly found in natural waters. Among the available treatment processes, the application of adsorbents in the column bed filter configuration is considered as a more advantageous setup due to its simplicity and almost unattended operation. Iron-based oxy-hydroxides (FeOOHs) are the main class of adsorbents studied so far for Sb uptake, while other solid phases or inorganic composites, including zero valent iron [12], graphene oxide [13,14], activated alumina [15], aerobic bio-granules [16], hydroxyapatite [4] and zeolites [17], were also reported as alternative active adsorption materials.

In general, the adsorption behavior of antimony onto FeOOHs is determined mainly by its speciation (as $\mathrm{Sb}(\mathrm{III})$ and/or $\mathrm{Sb}(\mathrm{V})$ ), its affinity with the different kinds of adsorbents, the $\mathrm{pH}$ of adsorption, interferences by other co-existing competing ions, and by secondary desorption processes [18-21]. Both $\mathrm{Sb}$ species form inner-sphere complexes when adsorbed on a $\mathrm{FeOOH}$ surface [22]. However, the literature results suggest that the adsorption of $\mathrm{Sb}$ (III) is almost independent of the applied $\mathrm{pH}$ value, whereas the adsorption capacity for $\mathrm{Sb}(\mathrm{V})$ significantly drops as the $\mathrm{pH}$ increases within the $\mathrm{pH}$ range of natural waters (6-8) and decreases further in the presence of certain competing anions such as phosphates.

Another important observation is that the surface of amorphous $\mathrm{FeOOH}$ may catalyze the oxidation of initially adsorbed $\mathrm{Sb}(\mathrm{III})$, leading to the partial desorption of $\mathrm{Sb}(\mathrm{V})$ back into the treated water $[23,24]$. This mechanism becomes more intense when applying iron-manganese oxy-hydroxides (Fe-MnOOH), due to the rapid oxidation of $\mathrm{Sb}(\mathrm{III})$ and the subsequent release of formed $\mathrm{Sb}(\mathrm{V})[25,26]$. Although this strategy promotes the advantage of converting antimony to the less toxic $S b(V)$ species, the result of this reaction is of doubtful use, since efficient adsorption results for $\mathrm{Sb}(\mathrm{V})$ can be provided only for acidic $\mathrm{pH}$ values (i.e., below 5); therefore, it is not particularly useful for drinking water applications.

From the practical point of view, the treatment/removal of antimony from water by using adsorbents has to be approached in a different way than in the system of As(III)/ As(V). Many studies indicate that commercial sorbent materials based on $\mathrm{FeOOH}$ developed for arsenic removal fail to be efficient for the removal of antimony. Particularly, granular ferric hydroxide (GFH), CFH12 or Bayoxide E33 have been tested in several studies, indicating a weak performance for antimony removal, i.e., one to two orders of magnitude below the corresponding values for arsenic, since the adsorption capacity at the residual concentration of $5 \mu \mathrm{g} / \mathrm{L}$ ranged between 0.03 and $0.65 \mathrm{mg} \mathrm{Sb} / \mathrm{g}$ [27-30]. 
The aim of this work is to determine the major parameters featuring an effective iron oxy-hydroxide adsorbent material that can enable a high potential for antimony uptake, i.e., able to provide a residual $\mathrm{Sb}$ concentration below the respective drinking water regulation, and to suggest a relatively simple preparation method that can create such a customized material. To the best of our knowledge, the application of this kind of $\mathrm{FeOOH}$ has not been previously reported and comprises a fully new approach in antimony removal options, which leaves the field for further improvements open. In this regard, a series of $\mathrm{FeOOH}$ was prepared by the precipitation of iron salts under different $\mathrm{pH}$ and redox potential values. The adsorption capacity of these adsorbents for $\mathrm{Sb}(\mathrm{III})$ and $\mathrm{Sb}(\mathrm{V})$ species was evaluated in comparison to commercial FeOOH- and Fe-MnOOH-based products, already used for arsenic treatment, by applying batch and column experimental protocols.

\section{Materials and Methods}

\subsection{Adsorbents}

In order to establish the correlation of structural and surface properties of $\mathrm{FeOOH}$ with their efficiency to capture/remove antimony, a series of samples were synthesized by oxidation-hydrolysis of $\mathrm{FeSO}_{4} \cdot \mathrm{H}_{2} \mathrm{O}$ under high redox potential and various $\mathrm{pH}$ values, using a laboratory two-stage continuous flow reactor [31]. The reaction setup was pumped with a $40 \mathrm{~g} / \mathrm{L} \mathrm{FeSO}_{4} \cdot \mathrm{H}_{2} \mathrm{O}$ solution at a $10 \mathrm{~L} / \mathrm{h}$ rate, whereas redox potential and $\mathrm{pH}$ were regulated by the addition of drops of $\mathrm{H}_{2} \mathrm{O}_{2}$ $(50 \% w / w)$ and $\mathrm{NaOH}(30 \% w / w)$, respectively. Particularly, in each synthesis, the $\mathrm{pH}$ was set at a constant value $(4,7,9)$ and for this condition the redox potential was controlled to the corresponding maximum point, before oxygen bubbles appear, i.e., from +410 to $+170 \mathrm{mV}$ for the specific $\mathrm{pH}$ range. Formed solids were collected from the outflow of the system and thickened using an Imhoff tank. The obtained sludge was washed, centrifuged and dried for $4 \mathrm{~h}$ at $110^{\circ} \mathrm{C}$. The material was ground either as fine powder (with size less than $63 \mu \mathrm{m}$ ) for the batch adsorption experiments, or as granules (with size $0.25-0.50 \mathrm{~mm}$ ) for the column tests. The specific surface area of the samples was determined by the volumetric method (BET) in the range $120-150 \mathrm{~m}^{2} / \mathrm{g}$. The production cost of such process scaled up to industrial-operation terms is estimated to be around $2 € / \mathrm{kg}$ split to $0.9 € / \mathrm{kg}$ for reagents, $0.2 € / \mathrm{kg}$ for energy, 0.4 for labor and $0.5 € / \mathrm{kg}$ for other (maintenance, packaging, depreciation, etc.) costs. For comparison reasons, the commercially available $\mathrm{FeOOH}$ and $\mathrm{Fe}-\mathrm{MnOOH}$ products approved for arsenic treatment, such as GFH $\left(237 \mathrm{~m}^{2} / \mathrm{g}\right)$, AquAsZero $\left(190 \mathrm{~m}^{2} / \mathrm{g}\right)$, Bayoxide $\left(135 \mathrm{~m}^{2} / \mathrm{g}\right)$ namely consisting of akagaenite, tetravalent manganese feroxyhyte and goethite, respectively, were also examined in this study.

\subsection{Batch Experiments}

Stock solutions of $\mathrm{Sb}(\mathrm{III})$ or $\mathrm{Sb}(\mathrm{V})(100 \mathrm{mg} / \mathrm{L})$ were prepared from reagent grade $\mathrm{Sb}_{2} \mathrm{O}_{3}$ and $\mathrm{K}\left[\mathrm{Sb}(\mathrm{OH})_{6}\right]$, respectively. Working standards were freshly prepared by proper dilution of the stock solutions in a test water matrix, containing the interfering ions of a typical natural water. The natural-like water was prepared according to National Sanitation Foundation (NSF) standard, containing $252 \mathrm{mg} \mathrm{NaHCO}, 12.14 \mathrm{mg} \mathrm{NaNO}, 0.178 \mathrm{mg} \mathrm{NaH} \mathrm{PO}_{4} \cdot \mathrm{H}_{2} \mathrm{O}, 2.21 \mathrm{mg} \mathrm{NaF}, 70.6 \mathrm{mg}$ $\mathrm{NaSiO}_{3} \cdot 5 \mathrm{H}_{2} \mathrm{O}, 147 \mathrm{mg} \mathrm{CaCl} \cdot 2 \mathrm{H}_{2} \mathrm{O}$ and $128.3 \mathrm{mg} \mathrm{MgSO} \cdot \cdot 7 \mathrm{H}_{2} \mathrm{O}$, diluted in $1 \mathrm{~L}$ of distilled water. Prior to adsorption experiments, $\mathrm{pH}$ was adjusted to the target value, by adding either $\mathrm{NaOH}$ or $\mathrm{HCl}$ of 0.1 or $0.01 \mathrm{~N}$. Adsorption batch experiments were carried out by placing 5-25 mg of adsorbents' fine powder, with size less than $63 \mu \mathrm{m}$, in $300 \mathrm{~mL}$ conical flasks and shaking with $200 \mathrm{~mL}$ of aqueous $\mathrm{Sb}(\mathrm{III})$ or $\mathrm{Sb}(\mathrm{V})$ solutions for $24 \mathrm{~h}$ at $20^{\circ} \mathrm{C}$. Initial antimony concentrations ranged between 100 and $5000 \mu \mathrm{g} / \mathrm{L}$ to provide equilibrium concentrations between 2 and $1000 \mu \mathrm{g} / \mathrm{L}$. Initial $\mathrm{pH}$ values were adjusted at 6, 7 and 8 and adsorption isotherms were recorded at each equilibrium $\mathrm{pH}$. At the end of each experiment, the suspensions were filtered through a $0.45 \mu \mathrm{m}$ pore-size membrane filter. The collected samples $(100 \mathrm{~mL})$ were first acidified by adding $1 \mathrm{~mL}$ of $8 \mathrm{~N} \mathrm{HNO}_{3}$ and then antimony species were stabilized in the $\mathrm{Sb}(\mathrm{V})$ form with the addition of $0.2 \mathrm{~mL}$ of $0.1 \mathrm{~N} \mathrm{KMnO}_{4}$. Initial and residual antimony 
concentrations were determined by Graphite Furnace Atomic Absorption Spectrophotometry, using a Perkin-Elmer AAnalyst 800 instrument, with a calibration curve of $\mathrm{Sb}(\mathrm{V})$ standards. The detection limit of the method, which was calculated from 7 replicates of 2-10 $\mu \mathrm{g} \mathrm{Sb} / \mathrm{L}$, was estimated to be $1.5 \mu \mathrm{g} / \mathrm{L}$.

\subsection{Kinetics}

The evolution of antimony concentration with contact time $(0-24 \mathrm{~h})$ was monitored during batch adsorption experiments, by introducing $20 \mathrm{mg}$ of adsorbent dispersed in $200 \mathrm{~mL}$ of $\mathrm{Sb}$ (III) solution in NSF water matrix with initial concentration $500 \mu \mathrm{g} / \mathrm{L}$ at pH 7 and $20^{\circ} \mathrm{C}$. Sampling was performed with higher frequency during initial treatment times, whereas it was performed at extended time intervals, when equilibrium was approached.

\subsection{Column Tests}

Rapid small-scale column tests (RSSCT) were performed to evaluate the efficiency of tested adsorbents in a full-scale system, by designing the experiments in such a way that would simulate a full-scale adsorption column with an Empty Bed Contact Time (EBCT) of $5 \mathrm{~min}$. This was achieved by operating a small-scale laboratory experiment with an EBCT 3 min, using a Reynolds-Schmidt numbers product of around 2000, and an hydraulic loading $q$ of $0.5 \mathrm{~L} / \mathrm{h}$. Granules of adsorbents with size $0.25-0.50 \mathrm{~mm}$ were introduced in laboratory glass columns (of $1.1 \mathrm{~cm}$ diameter and $40 \mathrm{~cm}$ height), equipped with PTFE valves and a glass frit to hold the material. Columns were filled at a height of $26 \mathrm{~cm}$ by granules of the qualified FeOOH adsorbent $\left(m_{\text {ads }}=15 \mathrm{~g}\right)$ and AquAsZero $\left(m_{\text {ads }}=12 \mathrm{~g}\right)$. The system was fed either by $\mathrm{Sb}(\mathrm{III})$ or $\mathrm{Sb}(\mathrm{V})$ solution $\left(C_{o}=100 \mu \mathrm{g} / \mathrm{L}\right)$ in NSF water matrix pumped from the top of the column. The equilibrium $\mathrm{pH}$ was adjusted to $7 \pm 0.1$. Water samples were periodically collected from the effluent and analyzed for the residual antimony concentration $\left(C_{e}\right)$. The adsorption capacity $Q$ (mg. Sb/g adsorbent) at each time $t$ was determined by the implementation of Equation (1):

$$
Q=\sum_{t=0}^{t}\left(C_{o}-C_{e}\right) \cdot q \cdot d t / m_{a d s}
$$

\subsection{Leaching Behavior}

Antimony desorption tests were performed by using the spent adsorbents from RSSCT experiments to check their compliance with the regulations for environmentally safe disposal. A given mass of the solid-loaded with $\mathrm{Sb}$ sample was placed in a container with a specific volume of a leaching solution, according to standard leaching test EN 12457 [32].

\section{Results}

\subsection{Adsorption Evaluation}

The optimum preparation conditions for the synthesized FeOOHs were determined according to their efficiency to remove antimony species from water, by evaluating the corresponding adsorption isotherms in the $\mathrm{pH}$ range commonly encountered in drinking water. Figure 1 presents the results for the representative adsorbents synthesized at $\mathrm{pH}$ values of 4, 7 and 9, which were tested in batch adsorption experiments for $\mathrm{Sb}(\mathrm{III})$ and $\mathrm{Sb}(\mathrm{V})$ removal from NSF water. The isotherms were extended to higher $\mathrm{Sb}$ concentrations than those usually encountered in natural water to better clarify the existence of any trend and to obtain a more accurate fitting of the results. It is demonstrated that all examined materials appear to be potentially efficient for $\mathrm{Sb}$ (III) uptake, with the maximum adsorption capacity achieved by the $\mathrm{FeOOH}$ synthesized at $\mathrm{pH} 4$, which in turn was qualified as the optimum adsorbent. By the fitting of the $\mathrm{Sb}$ (III) adsorption data by a Freundlich-type curve, an adsorption capacity at the residual concentration of $5 \mu \mathrm{g} / \mathrm{L}$ equal to $3.1 \mathrm{mg} / \mathrm{g}$ was estimated for the qualified adsorbent, which is abbreviated as $Q_{5}$ henceforth. However, the $Q_{5}$ value was decreased close to $2 \mathrm{mg} / \mathrm{g}$ when the synthesis procedure took place at neutral or alkaline $\mathrm{pH}$ values. On the other hand, the tested 
adsorbents were not proved able to achieve final $\mathrm{Sb}(\mathrm{V})$ concentrations below the regulation limit of $5 \mu \mathrm{g} / \mathrm{L}$, indicating very low capacities in the studied residual concentration range (Figure 1b).

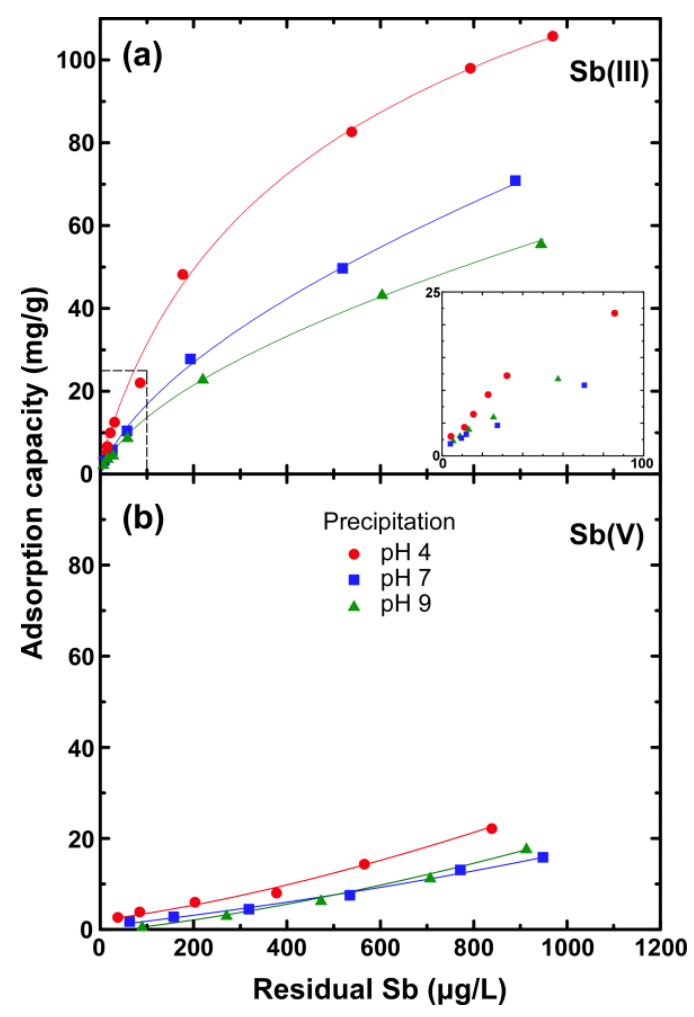

Figure 1. Antimony adsorption isotherms for synthesized FeOOH samples prepared by precipitation at $\mathrm{pH}$ values 4, 7 and 9; uptake of (a) $\mathrm{Sb}(\mathrm{III})$, and (b) $\mathrm{Sb}(\mathrm{V})$, dissolved in NSF water at $\mathrm{pH}$ 7. Inset: magnification of the isotherm in the concentration range $0-100 \mu \mathrm{g} / \mathrm{L}$.

The efficiency of the qualified FeOOH for $\mathrm{Sb}(\mathrm{III})$ adsorption was relatively stable in the water $\mathrm{pH}$ range of 6-7, where the dominant antimony form is $\mathrm{Sb}(\mathrm{OH})_{3}$ (Figure 2). However, the adsorption capacity slightly decreased when the adsorption took place either under more acidic ( $\mathrm{pH} 5)$ or more alkaline conditions ( $\mathrm{pH}$ 8). In addition, the qualified $\mathrm{FeOOH}$ was found to be more efficient for the removal of $\mathrm{Sb}(\mathrm{III})$, when compared to certain commercially available arsenic adsorbents.

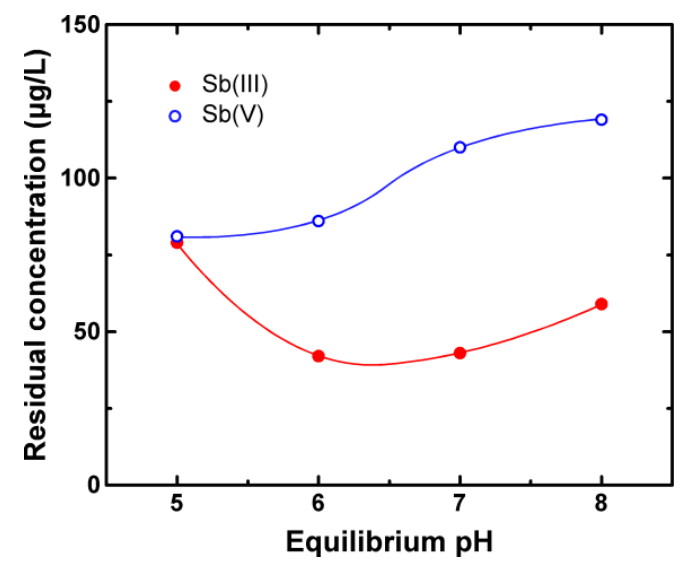

Figure 2. Influence of water $\mathrm{pH}$ on $\mathrm{Sb}$ species adsorption efficiency of qualified $\mathrm{FeOOH}$. Initial concentrations: $1000 \mu \mathrm{g} \mathrm{Sb}(\mathrm{III}) / \mathrm{L}, 250 \mu \mathrm{g} \mathrm{Sb}(\mathrm{V}) / \mathrm{L}$, Adsorbent $50 \mathrm{mg} / \mathrm{L}$, NSF water matrix, $20{ }^{\circ} \mathrm{C}$. Estimated loadings: $18.4-19.1 \mathrm{mg} / \mathrm{g}$ for $\mathrm{Sb}(\mathrm{III})$ and $2.6-3.4 \mathrm{mg} / \mathrm{g}$ for $\mathrm{Sb}(\mathrm{V})$. 
GFH and Bayoxide provided lower $Q_{5}$ values of $1.4 \mathrm{mg} / \mathrm{g}$ and $0.6 \mathrm{mg} / \mathrm{g}$, respectively, while AquAsZero was unable to reduce the residual Sb(III) below the limit value of $5 \mu \mathrm{g} / \mathrm{L}$ (Figure 3). Similarly, the commercial FeOOH adsorbents failed to meet the drinking water regulation limit for $\mathrm{Sb}(\mathrm{V})$ (data not shown).

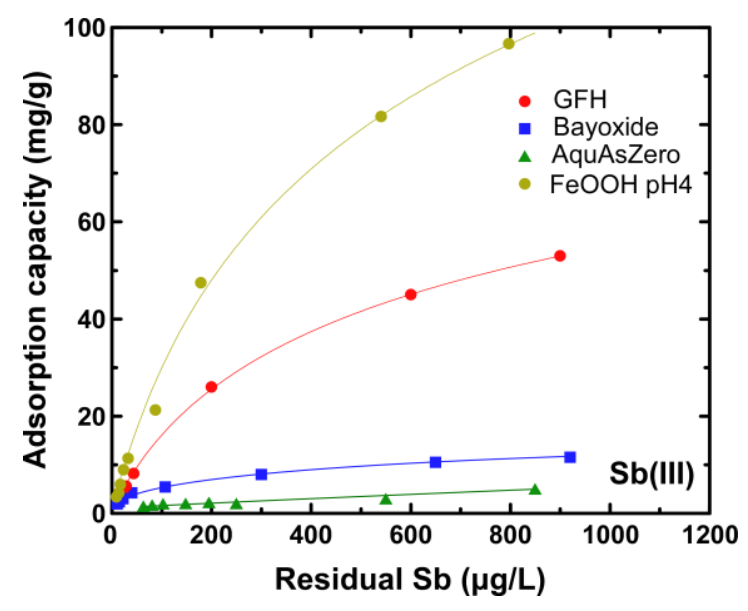

Figure 3. $\mathrm{Sb}$ (III) adsorption isotherms for GFH, Bayoxide and AquAsZero, which are commercially available adsorbents, in comparison to that of $\mathrm{FeOOH}$ prepared at $\mathrm{pH}$ 4. Experiments were conducted in NSF water matrix at $\mathrm{pH} 7$.

\subsection{Kinetics}

The evolution of the residual $\mathrm{Sb}(\mathrm{III})$ concentration by increasing the contact time during the batch experiments indicated a very rapid adsorption process, as $85 \%$ removal was observed within the first 10 min of contact time, while $96 \%$ of the equilibrium concentration was reached after the first hour. Figure 4 shows the kinetic data obtained for the $\mathrm{FeOOH}$ samples prepared at $\mathrm{pH}$ values of 4 (qualified $\mathrm{FeOOH}$ ) and 7. These experimental points were best fitted by a pseudo-second-order equation:

$$
\frac{t}{q_{t}}=\frac{1}{k q_{e}^{2}}+\frac{t}{q_{e}}
$$

where $t$ is the contact time (min), $q_{t}$ the adsorption capacity at this time $(\mathrm{mg} / \mathrm{g}), q_{e}$ the maximum capacity at equilibrium and $k$ the corresponding adsorption constant $(\mathrm{g} / \mathrm{mg} \cdot \mathrm{min})$. The fitting parameters $q_{\mathrm{e}}$ and $k$ were estimated to be $4.043 \mathrm{mg} / \mathrm{g}$ and $1.050 \mathrm{~g} /(\mathrm{mg} \cdot \mathrm{min})$, respectively, for the adsorbent prepared at $\mathrm{pH} \mathrm{4}$, while the corresponding values for the adsorbent prepared at $\mathrm{pH} 7$ were $3.326 \mathrm{mg} / \mathrm{g}$ and $0.823 \mathrm{~g} /(\mathrm{mg} \cdot \mathrm{min})$. Since the $\mathrm{FeOOH}$ samples were porous particles that were vigorously agitated during the adsorption period, it is reasonable to assume that the rate was not limited by mass transfer from the bulk liquid to the external surface of particles. The fact that the inclined lines (inset of Figure 4) do not pass through the origin verifies this assumption, indicating simultaneously that the limiting rate step of adsorption is attributed to the intraparticle diffusion effect and the plateau to the equilibrium [33]. 


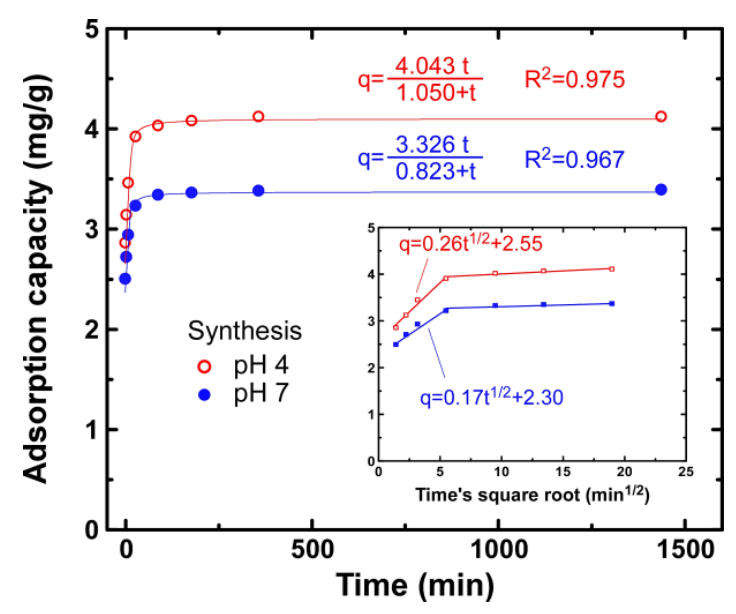

Figure 4. Kinetic data for $\mathrm{Sb}$ (III) adsorption fitted by a pseudo-second-order function for the $\mathrm{FeOOH}$ samples synthesized at $\mathrm{pH} 4$ (qualified $\mathrm{FeOOH}$ ) and 7, in NSF water adjusted at pH 7.

\subsection{Column Experiments}

Figure 5 summarizes the breakthrough curves for both $\mathrm{Sb}(\mathrm{III})$ and $\mathrm{Sb}(\mathrm{V})$ uptake by the qualified $\mathrm{FeOOH}$, as well as by the commercial AquAsZero. The commercial FeOOH products GFH and Bayoxide were not studied further here due to the previous publications of relevant data from large-scale column operations [30,34]. The results show that the efficiency of the qualified $\mathrm{FeOOH}$, prepared in this study, at the breakthrough concentration of $5 \mu \mathrm{g} / \mathrm{L}$, was approaching the $\mathrm{Q}_{5}$ value of $3 \mathrm{mg} / \mathrm{g}$ for $\mathrm{Sb}$ (III) removal, which is close to that defined by the batch adsorption experiments (Section 3.1). This $\mathrm{Q}_{5}$ value corresponds to $19.2 \times 10^{3}$ bed volumes. On the contrary, AquAsZero provided a $\mathrm{Q}_{5}$ value of only $0.2 \mathrm{mg} / \mathrm{g}$ for $\mathrm{Sb}(\mathrm{III})$ due to the oxidation of the latter to $\mathrm{Sb}(\mathrm{V})$. It should be clarified that AquAsZero was incorporated in this study just to illustrate the negative effect of oxidation in antimony removal. In any case, however, both adsorbents completely failed to capture the $\mathrm{Sb}(\mathrm{V})$ species even during the initial times of the column experiments, thus confirming the results of our batch experiments.

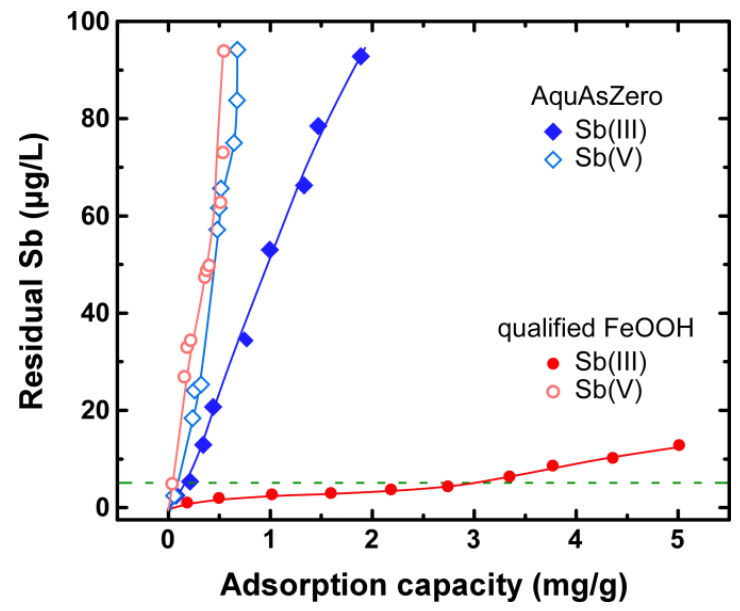

Figure 5. Breakthrough curves of granular qualified $\mathrm{FeOOH}$ and AquAsZero for $\mathrm{Sb}(\mathrm{III})$ and $\mathrm{Sb}(\mathrm{V})$ removal during RSSCT experiments. Initial concentration $100 \mu \mathrm{g} / \mathrm{L}$ in NSF water, adjusted at pH 7.

\subsection{Leaching Tests}

The spent adsorbents from the RSSCT experiments were subjected to leaching tests according to the EN 12457 procedure. The leaching results of the spent adsorbents loaded by $\mathrm{Sb}$ (III) indicated 
that the qualified $\mathrm{FeOOH}$ should be treated as inert waste, while AquAsZero should be treated as non-hazardous waste (Table 1). In contrast, both adsorbents should be characterized as non-hazardous wastes after $\mathrm{Sb}(\mathrm{V})$ uptake.

Table 1. Leaching characteristics of spent adsorbents tested in RSSCT experiments.

\begin{tabular}{ccc}
\hline Spent Adsorbent & Adsorption Load (mg.Sb/g) & EN12457-01 (mg/kg) $^{\mathbf{1}}$ \\
\hline & $S b(I I I)$ & \\
\hline Qualified FeOOH & 5.1 & 0.05 \\
AquAsZero & 3.4 & 0.22 \\
\hline & $S b(V)$ & 0.55 \\
\hline Qualified FeOOH & 0.30 & 0.68 \\
AquAsZero & 0.35 & \\
\hline 1 ${ }^{2}$ imit for inert wastes $0.06 \mathrm{mg} \mathrm{Sb} / \mathrm{kg}$ and limit for non-hazardous wastes $0.7 \mathrm{mg} \mathrm{Sb} / \mathrm{kg}$
\end{tabular}

\section{Discussion}

An overview of the examined materials, regarding their adsorption capacity for $\mathrm{Sb}$ (III) as derived by batch experiments, is presented in Figure 6. The $\mathrm{Q}_{5}$ values of synthesized FeOOHs were found to be at least $35 \%$ higher than the best commercially available adsorbent (GFH), while the capacity for the qualified $\mathrm{FeOOH}$ synthesized under acidic conditions ( $\mathrm{pH} 4)$ was almost double. The direct comparison of the $\mathrm{Q}_{5}$ values determined in this study with the relevant $\mathrm{Sb}$ adsorbents' efficiencies reported in literature was not possible because most of them focused on the maximum adsorption capacity, which is obtained at residual concentrations far higher than the drinking water regulation limit of $5 \mu \mathrm{g} / \mathrm{L}$. With respect to the synthesis conditions, the optimization of the adsorption behavior was observed when $\mathrm{FeOOH}$ adsorbent presents high surface charge density. . Specifically, a surface charge density of $2.5 \mathrm{mmol} \mathrm{OH}^{-} / \mathrm{g}$ was determined for the qualified $\mathrm{FeOOH}$, while the corresponding surface charge densities for the samples synthesized at $\mathrm{pH}$ values of 7 and 9 were 0.8 and $0.5 \mathrm{mmol}$ $\mathrm{OH}^{-} / \mathrm{g}$, respectively [31].

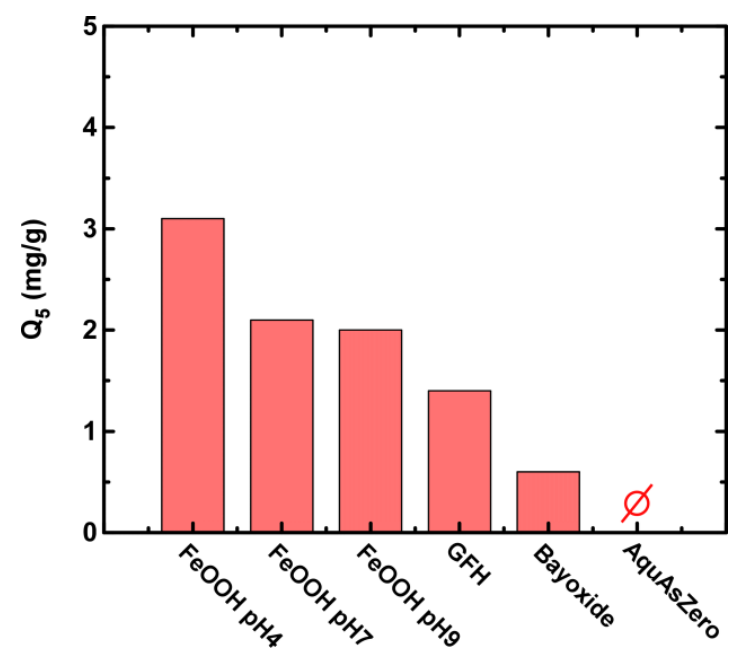

Figure 6. $\mathrm{Q}_{5}$ values for the synthesized FeOOHs at $\mathrm{pH} 4,7$ and 9 in comparison to commercial adsorbents at NSF water adjusted to $\mathrm{pH} 7$.

In addition, the $\mathrm{pH}$ dependence of the adsorption efficiency (Figure 2) should be correlated with the isoelectric point (IEP) of FeOOH in combination with the corresponding $\mathrm{Sb}$ (III) speciation (Figure 7). Particularly, at $\mathrm{pH}$ values below IEP (7.2), the net surface charge of $\mathrm{FeOOH}$ is positive, while at $\mathrm{pH}$ 
values above IEP it becomes negatively charged [31]. Therefore, in the NSF water matrix at a $\mathrm{pH}$ lower than 6, a part of the $\mathrm{Sb}(\mathrm{III})$ is present in the $\mathrm{Sb}(\mathrm{OH})_{2}{ }^{+}$form, which is repulsed by the positive surface of $\mathrm{FeOOH}$, resulting in a lower adsorption efficiency. Similarly, at $\mathrm{pH} 8$, part of the $\mathrm{Sb}$ (III) appears in the $\mathrm{Sb}(\mathrm{OH})_{4}{ }^{-}$form, which is repulsed by the negatively charged surface of FeOOH. In the case of $\mathrm{Sb}(\mathrm{V}), \mathrm{Sb}(\mathrm{OH})_{6}{ }^{-}$is the dominant form in the examined $\mathrm{pH}$ range (5-8). Therefore, adsorption efficiency is stable at the $\mathrm{pH}$ range of $5-6$, where the $\mathrm{FeOOH}$ surface is positively charged but decreases significantly as the water $\mathrm{pH}$ approaches IEP and diminishes at water $\mathrm{pH} 8$ where the $\mathrm{FeOOH}$ surface becomes negatively charged, thus repulsing antimonate oxyanions.

However, the $\mathrm{FeOOH}$ adsorbents were found to be effective only for $\mathrm{Sb}$ (III) uptake at levels able to fulfill the drinking water regulation limit of the EU. Their low affinity with $\mathrm{Sb}(\mathrm{V})$, which was observed in this study by both batch and column tests, was also verified by large-scale results. For instance, an adsorption capacity of $0.04 \mathrm{mg} / \mathrm{g}$ at a breakthrough concentration of $21 \mu \mathrm{g} / \mathrm{L}$ was determined at a Melivoia (Greece) water treatment plant using Bayoxide [30], and an adsorption capacity of $0.06 \mathrm{mg} / \mathrm{g}$ was reported in a demonstration project of the US EPA using GFH [34]. Even worse, AquAsZero (Fe-MnOOH products) appear ineffective for both $\mathrm{Sb}$ species. The low performance of AquAsZero should be correlated with the high oxidative potential, arising with the $\mathrm{Mn}^{4+}$ substitution in the oxy-hydroxide structure which results in the formation of $\mathrm{Sb}(\mathrm{V})$, showing very low affinity for adsorption.

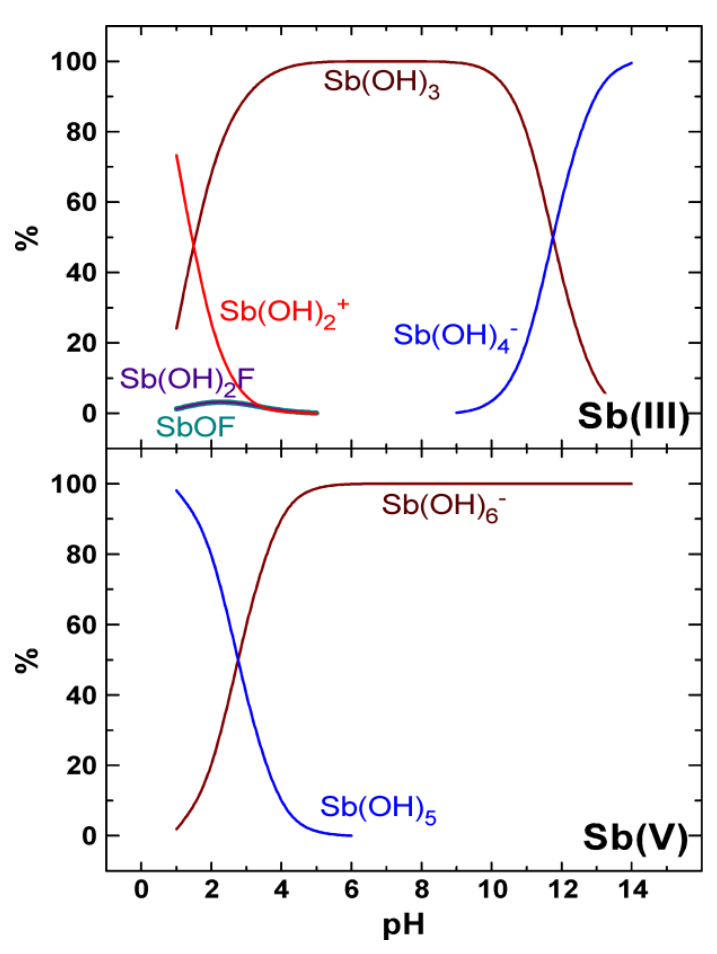

Figure 7. Speciation of $\mathrm{Sb}(\mathrm{III})$ and $\mathrm{Sb}(\mathrm{V})(100 \mu \mathrm{g} / \mathrm{L})$ in NSF water at $20^{\circ} \mathrm{C}$. Diagrams derived by Visual MINTEQ 3.0 (http:/ / vminteq.lwr.kth.se).

\section{Conclusions}

The developed positively charged $\mathrm{FeOOH}$ adsorbent may be applied as an efficient $\mathrm{Sb}$ (III) adsorbent, because it showed improved adsorption capacity under reliable water treatment conditions. Considering that the cost of the qualified $\mathrm{FeOOH}$ would be similar to that of the commercial $\mathrm{FeOOH}$ adsorbents $(9 \pm 1 € / \mathrm{kg})$, the adsorbent cost is estimated to be close to $30 \pm 3.4 € / 10^{3} \mathrm{~m}^{3}$ for every $10 \mu \mathrm{g} \mathrm{Sb}(\mathrm{III}) / \mathrm{L}$ removed. For the water treatment cost estimation, the energy cost $(10 \pm 1) € / 10^{3} \mathrm{~m}^{3}$ and labor cost $(10 \pm 5) € / 10^{3} \mathrm{~m}^{3}$ should be superadded, though they do not depend on the $\mathrm{Sb}(\mathrm{III})$ 
concentration. Removal of $\mathrm{Sb}(\mathrm{V})$, which is the stable form in oxygenated groundwater, may therefore require a primary reduction to $\mathrm{Sb}(\mathrm{III})$ and then sorption of $\mathrm{Sb}$ (III) onto FeOOHs.

Acknowledgments: This work was supported by the European Commission FP7/Research for SMEs "AquAsZero", Project No.: 232241.

Author Contributions: Anastasios I. Zouboulis and Manassis Mitrakas conceived, designed and supervised the experiments. Vasiliki Papadopoulou, Sofia Tresintsi and Evgenios Kokkinos performed the synthesis and adsorption experiments. Ioannis A. Katsoyiannis analyzed adsorption and kinetic data. Konstantinos Simeonidis and Manassis Mitrakas wrote the paper with the contribution of all co-authors.

Conflicts of Interest: The authors declare no conflict of interest.

\section{References}

1. World Health Organization. Antimony in Drinking-Water; Background Document for Preparation of WHO Guidelines for Drinking-Water Quality; WHO/SDE/WSH/03.04/74; World Health Organization: Geneva, Switzerland, 2003.

2. US Environmental Protection Agency. Edition of the Drinking Water Standards and Health Advisories; Office of Water, US Environmental Protection Agency: Washington, DC, USA, 2012.

3. European Union. Council Directive 98/83/EC on the Quality of Water Intended for Human Consumption; L330/32; Official Journal of the European Union: Brussels, Belgium, 1998.

4. Leyva, A.G.; Marrero, J.; Smichowski, P.; Cicerone, D. Sorption of antimony onto hydroxyapatite. Environ. Sci. Technol. 2001, 35, 3669-3675. [CrossRef] [PubMed]

5. Wilson, N.J.; Craw, D.; Hunter, K. Antimony distribution and environmental mobility at an historic antimony smelter site, New Zealand. Environ. Pollut. 2004, 129, 257-266. [CrossRef] [PubMed]

6. Ungureanu, G.; Santos, S.; Boaventura, R.; Botelho, C. Arsenic and antimony in water and wastewater: Overview of removal techniques with special reference to latest advances in adsorption. J. Environ. Manag. 2015, 151, 326-342. [CrossRef] [PubMed]

7. Mubarak, H.; Chai, L.-Y.; Mirza, N.; Yang, Z.-H.; Pervez, A.; Tariq, M.; Shaheen, S.; Mahmood, Q. Antimony (Sb)-Pollution and removal techniques-Critical assessment of technologies. Toxicol. Environ. Chem. 2015, 97, 1296-1318. [CrossRef]

8. Gannon, K.; Wilson, D.J. Removal of Antimony from Aqueous Systems. Sep. Sci. Technol. 1986, 21, 475-493. [CrossRef]

9. Wu, Z.; He, M.; Guo, X.; Zhou, R. Removal of antimony(III) and antimony(V) from drinking water by ferric chloride coagulation: Competing ion effect and the mechanism analysis. Sep. Purif. Technol. 2010, 76, 184-190. [CrossRef]

10. Guo, X.; Wu, Z.; He, M. Removal of antimony $(\mathrm{V})$ and antimony(III) from drinking water by coagulation-flocculation-sedimentation (CFS). Water Res. 2009, 43, 4327-4335. [CrossRef] [PubMed]

11. Kang, M.; Kamei, T.; Magara, Y. Comparing polyaluminum chloride and ferric chloride for antimony removal. Water Res. 2003, 37, 4171-4179. [CrossRef]

12. Xu, C.; Zhang, B.; Zhu, L.; Lin, S.; Sun, X.; Jiang, Z.; Tratnyek, P.G. Sequestration of Antimonite by Zerovalent Iron: Using Weak Magnetic Field Effects to Enhance Performance and Characterize Reaction Mechanisms. Environ. Sci. Technol. 2016, 50, 1483-1491. [CrossRef] [PubMed]

13. Leng, Y.; Guo, W.; Su, S.; Yi, C.; Xing, L. Removal of antimony(III) from aqueous solution by graphene as an adsorbent. Chem. Eng. J. 2012, 211-212, 406-411. [CrossRef]

14. Dong, S.; Dou, X.; Mohan, D.; Pittman, C.U.; Luo, J. Synthesis of graphene oxide/schwertmannite nanocomposites and their application in $\mathrm{Sb}(\mathrm{V})$ adsorption from water. Chem. Eng. J. 2015, 270, 205-214. [CrossRef]

15. Xu, Y.; Ohki, A.; Maeda, S. Adsorption and removal of antimony from aqueous solution by an activated Alumina. Toxicol. Environ. Chem. 2001, 80, 133-144. [CrossRef]

16. Wang, L.; Wan, C.; Zhang, Y.; Lee, D.-J.; Liu, X.; Chen, X.; Tay, J.-H. Mechanism of enhanced Sb(V) removal from aqueous solution using chemically modified aerobic granules. J. Hazard. Mater. 2015, 284, 43-49. [CrossRef] [PubMed]

17. Wingenfelder, U.; Furrer, G.; Schulin, R. Sorption of antimonate by HDTMA-modified zeolite. Microporous Mesoporous Mater. 2006, 95, 265-271. [CrossRef] 
18. He, Z.; Liu, R.; Liu, H.; Qu, J. Adsorption of $\mathrm{Sb}(\mathrm{III})$ and $\mathrm{Sb}(\mathrm{V})$ on Freshly Prepared Ferric Hydroxide (FeOxHy). Environ. Eng. Sci. 2015, 32, 95-102. [CrossRef] [PubMed]

19. Guo, X.; Wu, Z.; He, M.; Meng, X.; Jin, X.; Qiu, N.; Zhang, J. Adsorption of antimony onto iron oxy-hydroxides: Adsorption behavior and surface structure. J. Hazard. Mater. 2014, 276, 339-345. [CrossRef] [PubMed]

20. Vithanage, M.; Rajapaksha, A.U.; Dou, X.; Bolan, N.S.; Yang, J.E.; Ok, Y.S. Surface complexation modelling and spectroscopic evidence of antimony adsorption on iron-oxide-rich red earth soils. J. Colloid Interface Sci. 2013, 406, 217-224. [CrossRef] [PubMed]

21. Lu, H.; Zhu, Z.; Zhang, H.; Zhu, J.; Qiu, Y. Simultaneous removal of arsenate and antimonate in simulated and practical water samples by adsorption onto $\mathrm{Zn} / \mathrm{Fe}$ layered double hydroxide. Chem. Eng. J. 2015, 276, 365-375. [CrossRef]

22. Qi, P.; Pichler, T. Sequential and simultaneous adsorption of $\mathrm{Sb}(\mathrm{III})$ and $\mathrm{Sb}(\mathrm{V})$ on ferrihydrite: Implications for oxidation and competition. Chemosphere 2016, 145, 55-60. [CrossRef] [PubMed]

23. Leuz, A.K.; Mönch, H.; Johnson, C.A. Sorption of $\mathrm{Sb}(\mathrm{III})$ and $\mathrm{Sb}(\mathrm{V})$ to goethite: Influence on $\mathrm{Sb}(\mathrm{III})$ oxidation and mobilization. Environ. Sci. Technol. 2006, 40, 7277-7282. [CrossRef] [PubMed]

24. Belzile, N.; Chen, Y.W.; Wang, Z. Oxidation of antimony(III) by amorphous iron and Manganese oxyhydroxides. Chem. Geol. 2001, 174, 379-387. [CrossRef]

25. Xu, W.; Wang, H.; Liu, R.; Zhao, X.; Qu, J. The mechanism of antimony(III) removal and its reactions on the surfaces of Fe-Mn Binary Oxide. J. Colloid Interface Sci. 2011, 363, 320-326. [CrossRef] [PubMed]

26. Liu, R.; Liu, F.; Hu, C.; He, Z.; Liu, H.; Qu, J. Simultaneous removal of Cd(II) and Sb(V) by Fe-Mn binary oxide: Positive effects of $\mathrm{Cd}(\mathrm{II})$ on $\mathrm{Sb}(\mathrm{V})$ adsorption. J. Hazard. Mater. 2015, 300, 847-854. [CrossRef] [PubMed]

27. Sazakli, E.; Zouvelou, S.V.; Kalavrouziotis, I.; Leotsinidis, M. Arsenic and antimony removal from drinking water by adsorption on granular ferric oxide. Water Sci. Technol. 2015, 71, 622-629. [CrossRef] [PubMed]

28. Ilavský, J.; Barloková, D.; Munka, K. Antimony Removal from Water by Adsorption to Iron-Based Sorption Materials. Water Air Soil Pollut. 2015, 226, 2238. [CrossRef]

29. Kolbe, F.; Weiss, H.; Morgenstern, P.; Wennrich, R.; Lorenz, W.; Schurk, K.; Stanjek, H.; Daus, B. Sorption of aqueous antimony and arsenic species onto akaganeite. J. Colloid Interface Sci. 2011, 357, 460-465. [CrossRef]

30. Tresintsi, S.; Simeonidis, K.; Zouboulis, A.; Mitrakas, M. Comparative study of As(V) removal by ferric coagulation and oxy-hydroxides adsorption: Laboratory and full-scale case studies. Desalin. Water Treat. 2013, 51, 2872-2880. [CrossRef]

31. Tresintsi, S.; Simeonidis, K.; Vourlias, G.; Stavropoulos, G.; Mitrakas, M. Kilogram-scale synthesis of iron oxy-hydroxides with improved arsenic removal capacity: Study of Fe(II) oxidation-precipitation parameters. Water Res. 2012, 46, 5255-5267. [CrossRef] [PubMed]

32. European Committee for Standardization. 2002. EN 12457-2: Characterization of Waste-Leaching-Compliance Test for Leaching of Granular Waste Materials and Sludges-Part 2: One Stage Batch Test at Liquid to Solid Ratio of $10 \mathrm{~L} / \mathrm{kg}$ for Materials with Particle Size below $4 \mathrm{~mm}$ (without or with Size Reduction). European Standard; European Committee for Standardization: Brussels, Belgium, 2002.

33. Tripathy, S.S.; Raichur, A.M. Enhanced adsorption of activated alumina by impregnation with alum for removal of As(V) from water. Chem. Eng. J. 2008, 138, 179-186. [CrossRef]

34. Cumming, L.J.; Chen, A.S.C.; Wang, L. Arsenic and Antimony Removal from Drinking Water by Adsorption Media, US EPA Demonstration Project at South Truckee Meadows General Improvement District (STMGID); NV, Final Performance Evaluation Report; EPA/600/R-09/016; US Environmental Protection Agency: Washington, DC, USA, February 2009.

(C) 2017 by the authors; licensee MDPI, Basel, Switzerland. This article is an open access article distributed under the terms and conditions of the Creative Commons Attribution (CC BY) license (http://creativecommons.org/licenses/by/4.0/). 